\title{
Tecnologia, aids e ética em pesquisa
}

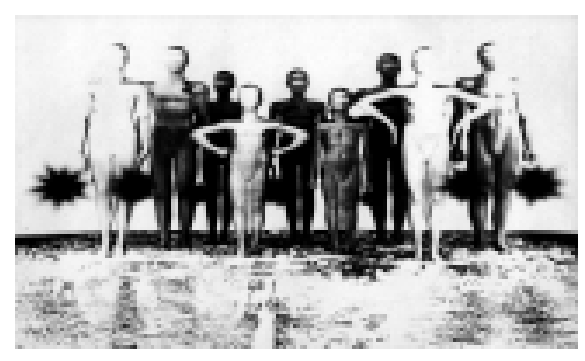

Mário Scheffer ${ }^{1}$

\begin{abstract}
De como a doença que desafia pesquisadores em todo o mundo pode ser o melhor exemplo sobre os tantos interesses que evidenciam o conflito entre o avanço da ciência e a preservação da dignidade humana.
\end{abstract}

Os avanços tecnológicos aplicados à Medicina $e$ as conquistas da tecnociência que beneficiam o homem dependem, na maioria das vezes, de experimentos realizados nos próprios seres humanos. Daí a relevância da correlação entre ética e produção de tecnologia em saúde, aqui entendida como o desenvolvimento de uma nova droga, vacina, equipamento, exame, insumo, dispositivo ou procedimento útil à prevenção, diagnóstico ou tratamento.

Além da metodologia adequada, toda pesquisa deve ser conduzida dentro de padrões éticos aceitáveis de respeito aos indivíduos (autonomia), de beneficência $e$ justiça. O Código de Nuremberg, a Declaração de Helsinque e as Diretrizes Internacionais para Pesquisas Biomédicas Envolvendo Seres Humanos são alguns documentos internacionais periodicamente atualizados $e$ balizadores de condutas éticas.

No Brasil, a pesquisa em seres humanos foi normatizada pela primeira vez em 1988, pelo Conselho Nacional de Saúde, em ação que não teve repercussão significativa junto à comunidade médica e científica. Hoje, no entanto, o início da construção de uma nova cultura de ética em pesquisa no país já é uma realidade. Trata-se do resultado da implementação da Resolução 196/96, também do Conselho Nacional de Saúde, que atualiza as regras de 1988 , incorpora as diretrizes internacionais e delimita direitos $e$ deveres da comunidade científica e dos sujeitos das pesquisas.

A Resolução 196 nasceu de intenso debate, com participação de todos os setores interessados, constituindo um exercício do legítimo controle social em saúde. Além da Comissão Nacional de Ética em Pesquisa (CONEP), a Resolução cria os Comitês de Ética em Pesquisa (CEP), que já somam mais de duzentos no país. Um dos maiores avanços foi assegurar a composição colegiada multidisciplinar dessas instâncias, impedindo a hegemonia de uma categoria profissional, como ocorre nas Comissões de Ética Médica. Não raro os CEPs contam com juristas, teólogos, sociológos, filósofos, entre outros especialistas. Outro fato novo é a possibilidade de participação do usuário ou representante da comunidade pesquisada.

Se por um lado o cenário é propício à prática da ética em pesquisa, torna-se imprescindível ressaltar que um longo caminho ainda precisa ser percorrido. No

\footnotetext{
${ }^{1}$ Ativista da luta contra a Aids, diretor do Grupo Pela Vidda/São Paulo e representante dos usuários no Conselho Nacional de Saúde.
} 
Brasil e no mundo o homem ainda é cobaia de pesquisadores que, em nome do progresso da ciência, colocam outros interesses acima do valor mais básico a ser preservado: a dignidade do ser humano.

\section{A Aids como paradigma}

Milhares de pesquisas, realizadas hoje no Brasil e no exterior com soropositivos $e$ doentes de Aids, avaliam a eficácia de novos fármacos, vacinas, testes diagnósticos, novas combinações de drogas e novos procedimentos clínicos. A pesquisa com humanos é o único meio confiável para obtenção de medicamentos anti-HIV cada vez mais potentes, de uma vacina preventiva eficaz, de um melhor acompanhamento $e$ tratamento dos já infectados. É a tecnologia a serviço da melhoria da qualidade e da quantidade de vida da população com HIV.

Por causa da gravidade da infecção, da inexistência de cura, do caráter epidêmico e, principalmente, da resposta comunitária $e$ mobilização das pessoas afetadas através dos grupos de luta contra a Aids, houve uma revolução na velocidade e nas discussões éticas sobre pesquisas e incorporações tecnológicas, sobretudo de novas drogas $e$ exames laboratoriais.

Um exemplo: fora do campo da aids, para uma substância transformar-se em medicamento são necessários de dez a doze anos. No caso da Aids, esse tempo foi reduzido para dois, três anos.

Cerca de vinte drogas anti-retrovirais, com centenas de combinações entre elas, compõem o potente arsenal terapêutico hoje disponível contra o vírus. Ao lado de exames complementares como a contagem de carga viral, CD4 e o teste de genotipagem, que ajudam a monitorar a evolução da infecção, assistimos à diminuição em mais de $50 \%$ do número de óbitos. Fala-se até da cronificação da doença, apesar das dificuldades de adesão ao regime medicamentoso, dos efeitos colaterais graves e do desconhecimento da eficácia do "coquetel" a longo prazo.

Há um batalhão de cientistas por trás do vertiginoso e frenético avanço tecnológico para conter a epidemia, em todos os campos do conhecimento. Há também interesses econômicos poderosos envolvidos em cada pesquisa. Assim, sobram exemplos paradigmáticos de triunfos e abusos na condução de experimentos e ensaios clínicos.

\section{Escândalo internacional}

Em 1999, a comunidade médica e científica internacional envolveu-se em intenso debate sobre ensaios clínicos com anti-retrovirais nos países em desenvolvimento.

O motivo foi pesquisa realizada na Tailândia para avaliar a segurança $e$ a eficácia do AZT na prevenção da transmissão vertical do HIV, tanto no final da gravidez quanto durante o trabalho de parto. $\mathrm{O}$ estudo manteve um grupo-placebo, ignorando a existência de uma terapêutica eficaz já comprovada para o tratamento de mulheres grávidas soropositivas.

O uso do AZT em cinco doses diárias, a partir da $14^{\mathrm{a}}$ semana de gestação, e a administração intravenosa da droga durante o trabalho de parto e como xarope para o recém-nascido durante seis semanas é o que vem sendo usado desde 1994 nos países ricos e no Brasil, inclusive. Custa cerca de US\$ 800 e diminui em até $70 \%$ o risco de transmissão. Em busca de um regime mais barato e menos complexo, o tratamento alternativo pesquisado na Tailândia administrou apenas duas doses do AZT, nas quatro últimas semanas da gravidez e oralmente durante o trabalho de parto. O custo caiu para US\$50 e o risco de trasmissão foi igualmente reduzido.

O grupo-placebo é condenável pois os sujeitos deixam de receber um regime efetivo já conhecido, que pode prevenir ou reduzir danos, incluindo até a morte de mães e filhos. Nos países desenvolvidos, estudos com placebo são considerados anti-éticos quando já se conhece tratatamento eficaz. Por que então a mesma regra não é aplicada para os países em desenvolvimento?

Pesquisadores e médicos dos EUA e de diversos países, reunidos em Atlanta, em 
junho de 1998, assinaram documento de apoio ao desenho da pesquisa, publicado pela prestigiada Revista Lancet. E o mais grave: a Organização Mundial da Saúde (OMS) tem reforçado os argumentos para justificar a realização de estudos dessa natureza.

Trata-se de ação orquestrada pelo imperativo econômico, valendo-se da urgência e da gravidade da epidemia nos países pobres. Há, inclusive, a campanha explícita de que seja alterada a Declaração de Helsinque: ao pressuposto ético de que os melhores métodos comprovados de diagnóstico $e$ tratamento devem estar disponíveis para todos os pesquisados propõem o acréscimo do uso justificado do placebo, sempre que no país onde se realiza o estudo não existir nenhum tratamento disponível.

Estamos, assim, diante da eminência da atrocidade consentida.

\section{Um caso brasileiro}

Há cinco anos o Brasil foi escolhido pela multinacional farmacêutica Merck Sharp \& Dohme para a realização de um ensaio clínico multicêntrico com seu anti-retroviral inibidor da protease, o indinavir (Crixivan). Isso aconteceu porque na época existia no país grande quantidade de pacientes com HIV que nunca haviam recebido nenhum tipo de tratamento, população ideal para a pesquisa.

No final de 1994 teve início o recrutamento. Milhares de pessoas, seduzidas pela propaganda de um remédio promissor $e$ pelas condições de tratamento diferenciado, correram aos centros de pesquisa, todos de reconhecida excelência: Hospital Emílio Ribas, Hospital das Clínicas da USP, Hopital das Clínicas da Unicamp, Hospital São Paulo da Unifesp e CRT/Aids.

Foram selecionados novecentos pacientes randomizados em três grupos de pesquisa: os que tomavam AZT isoladamente; os que recebiam $A Z T$ e indinavir e os que tomavam apenas indinavir. Em agosto de 1996, após pressão da comunidade pesquisada, foi acrescentada a droga 3TC (Epivir) aos dois primeiros grupos.
Apesar do termo de consentimento livre e esclarecido, os pacientes entravam no estudo sem consciência dos riscos potenciais. Sequer estavam embuídos do propósito de contribuir com a ciência. Na verdade, corriam atrás da droga potencialmente inovadora não disponível no mercado ou na rede pública naquele momento do início da pesquisa. Encantavam-se igualmente com o atendimento "vip", o acesso a consultas de hora marcada $e$ exames em laboratório privado.

Durante todo o estudo os grupos e organizações não governamentais representantes dos sujeitos da pesquisa dialogaram com a Merck e seus pesquisadores, sem, no entanto, obterem respostas satisfatórias para sérios questionamentos. A saber:

1 A pesquisa fornecia tratamento pior que o da rede pública

Em outubro de 1995 foram divulgados estudos apontando a inferioridade do tratamento com AZT isoladamente (monoterapia), comparado com o uso combinado de AZT com outra droga. Em março de 1996 a monoterapia com AZT já havia sido abolida na rede pública, que passou a fornecer a combinação de duas drogas. Mesmo assim, a Merck e seus pesquisadores mantiveram cerca de trezentos pacientes em monoterapia com AZT até, pelo menos, agosto de 1996. Não foram poucos os voluntários prejudicados, com perda de peso $e$ desenvolvimento de doenças oportunistas.

2 Insistia na monoterapia com indinavir Desde novembro de 1995 a publicação de artigos de especialistas $e$ a divulgação de estudos preliminares apontavam o rápido desenvolvimento de resistência do HIV ao indinavir (Crixivan), quando administrado isoladamente. Mesmo assim a pesquisa mantinha trezentos pacientes tomando indinavir isoladamente, sendo que nenhum médico, inclusive os que comandavam a pesquisa, prescreviam monoterapia em seus consultórios, fora do estudo. 
3 Negava ao voluntário informações sobre sua saúde

Na ocasião, já havia dois anos que a medida da carga viral, além da contagem de células CD4, vinha sendo utilizada para avaliar a eficácia de um tratamento com antivirais. Mesmo assim, os pesquisadores se recusaram a fornecer aos voluntários da pesquisa os resultados da carga viral, imprescindível para monitorar a evolução da infecção pelo HIV. Os marcadores laboratoriais eram subestimados e a terapia era alterada só após desenvolvimento de doenças oportunistas.

O estudo acabou, a droga em questão revelou-se uma arma poderosa contra a infecção pelo HIV, mas até hoje as denúncias, que tiveram repercussão pública dentro $e$ fora do país, não foram devidamente apuradas.

Nesse caso, a legitimidade do discurso leigo dos ativistas da luta contra a Aids apesar de ter sido duramente contestada - foi decisiva para questionar os limites éticos na busca do avanço tecnológico.

\section{A título de reflexão}

A partir da experiência de acompanhar criticamente pesquisas em HIV/Aids, temos debatido com os potenciais sujeitos de pesquisas e seus grupos representativos algumas reflexões:

10 paciente não deve assinar documento consentindo imediatamente com a pesquisa. Deve levar para casa, reler, refletir, procurar um grupo de luta contra a Aids, tirar todas as dúvidas restantes com o médico da pesquisa $e$, se optar por entrar no estudo, não abandonar seu médico de confiança. Ao entrar na pesquisa deve estar consciente de que pode não obter benefício algum e de que está apenas contribuindo com a ciência.

20 paciente não deve ser voluntário apenas "seduzido" pelas aparentes vantagens, como um tratamento diferente do encontrado na rede pública, consulta com hora marcada, exames com periodicidade certa, atenção diferenciada etc. Além disso, é bom prestar atenção na forma de propaganda da pesquisa para recrutamento dos voluntários. Muitas vezes ela é enganosa, prometendo benefícios que ainda são meras suposições.

3 Defendemos que o CEP da instituição conte, na análise do protocolo de pesquisa, com a participação de um soropositivo ou representante de grupo de luta contra a Aids, mesmo que seja na categoria ad hoc.

4 Os dados sobre a verba envolvida na pesquisa, do salário dos pesquisadores aos gastos por paciente, devem ser transparentes. A pesquisa não pode ser motivo de discriminação de médicos e pacientes na rotina do hospital ou unidade de saúde onde ela se realiza. Nem os médicos envolvidos devem receber salários exorbitantes, destoando dos demais colegas; nem os pacientes receber "privilégios" que caracterizem uma "fila dupla" de atendimento, em relação aos demais.

5 A pesquisa deve trazer benefício direto para os soropositivos brasileiros. Se eficaz, a droga testada - no caso da pesquisa de novos medicamentos -, deve estar disponível imediatamente em nossa rede pública de saúde e não apenas no país de origem, uma vez que a grande maioria das pesquisas são conduzidas do exterior por multinacionais.

6 Algumas pesquisas só trazem benefício para o pesquisador, que ganha pontos na vida acadêmica, vê o resultado publicado em revista científica e dá a volta ao mundo para participar de conferências e congressos com passagem e estadia custeadas pelo laboratório patrocinador da pesquisa. A instituição ganha visibilidade e dinheiro, a indústria consegue informações preciosas sobre a droga e para o paciente, muitas vezes, só resta a experiência de ter sido cobaia.

7 A luta contra a Aids demonstra o quanto é imensurável a importância dos avanços científicos e tecnológicos incorporados pela biomedicina para o homem. Mas é uma questão de humanidade aliar estes avanços à ética em pesquisa. Sem esquecer que hoje há instrumentos para isso. 